\title{
Caducidad vs \\ Consumo preferente
}

\section{José Ángel Pérez Álvarez, investigador en la UMH, asegura que en España existe una desinformación generalizada en cuestiones alimenticias}

\section{F. N. Maillo / Borja G. Moya}

El Gobierno heleno ha autorizado recientemente que los supermercados y las tiendas al por menor del país puedan ampliar el tiempo de venta y de exposición de algunos alimentos en sus estantes. Esta medida permite reducir el precio de artículos cuya fecha de consumo preferente sea próxima, una recomendación que contempla la legislación europea.

Sin embargo, José Ángel Pérez Álvarez, director del Grupo de Investigación IPOA del Departamento de Tecnología Agroalimentaria de la $\mathrm{UMH}$, además de vicerrector adjunto de Doctorado y Recursos Bibliográficos, afirma que la desinformación generalizada en cuestiones de alimentación ha provocado que la noticia haya despertado cierta alarma social, principalmente porque los consumidores confunden la fecha de consumo preferente $y$ la fecha de caducidad: mientras que la primera marca el periodo en que las propiedades del producto (calidad) se mantienen óptimas, la fecha de caducidad hace referencia a la inocuidad (seguridad y salubridad).

El decreto ministerial aprobado en Grecia fija un límite de tiempo en que se pueden seguir comercializando los alimentos, excepto los perecederos como carnes, pescados, huevos y lácteos. La ley ha fijado que los productos cuya

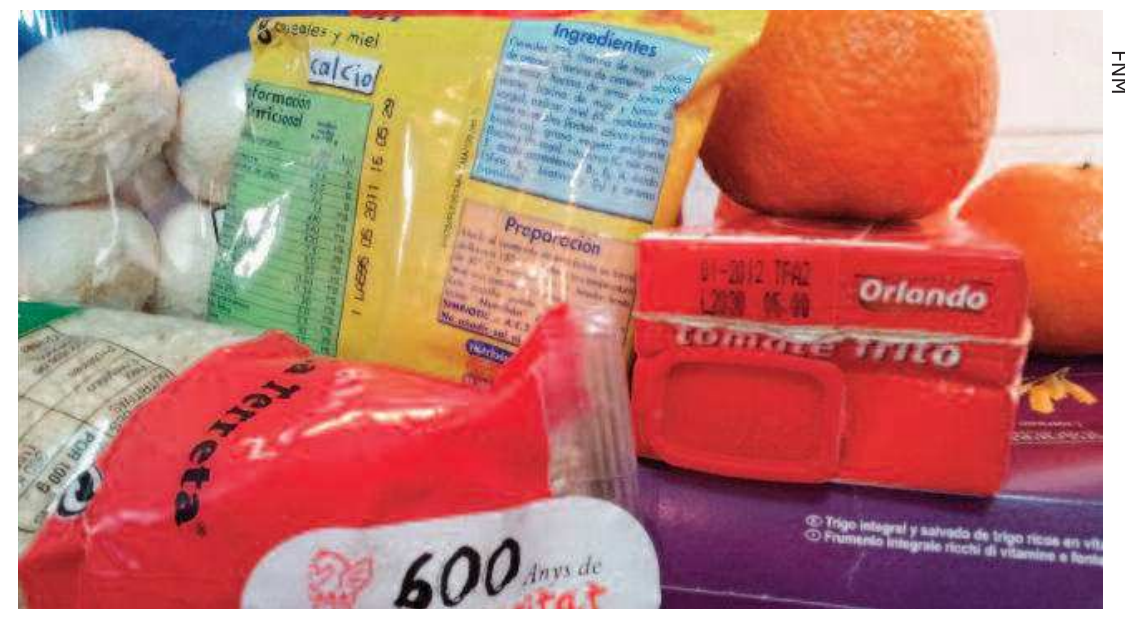

España es el sexto país europeo que más comida desecha

fecha de consumo preferente se indique por el día y el mes podrán seguir en los lineales una semana más, los que muestren el mes y el año amplían su vida útil un mes, y que los que informan sólo del año obtienen una prórroga de un trimestre. Esta fecha de consumo preferente establece el margen de tiempo en que el productor garantiza las propiedades óptimas (calidad) del producto, como el aroma, el sabor, el color y, por supuesto, la ausencia de crecimiento microbiano. Una vez superada esta fecha, la degradaLa fecha de consumo
preferente garantiza la
calidad del producto y
la caducidad establece
inocuidad del alimento

ción de las características del alimento es paulatina, pero, si las técnicas de conservación y manipulación son las idóneas, la inocuidad del alimento permanece.
De acuerdo con Pérez Álvarez, el sistema alimentario en España es muy riguroso y permite tomar decisiones a tiempo: las empresas reducen su producción para evitar los excedentes, pero si existe sobrante se deriva con frecuencia a los bancos de alimentos o campañas específicas, o también pueden venderse como oferta días antes de esa fecha.

\section{Más control y menos gasto}

Un informe publicado por el Parlamento Europeo a finales de 2011 concluía que España es el sexto país europeo que más comida desecha (cerca de 7,7 millones de toneladas de alimentos al año), siendo el principal motivo para el despilfarro las dudas en relación a la fecha de caducidad. De acuerdo con el profesor de la $\mathrm{UMH}$, una mejor información sobre el significado de las etiquetas podría reducir el riesgo de intoxicaciones, especialmente con los ancianos que han vivido la 
época de la postguerra y "suelen almacenar en la despensa por lo que pueda pasar". Algo similar ocurre con los niños, a los que nadie les enseña a leer las etiquetas y generalmente entienden que, una vez pasada la fecha que pone en el envoltorio o la tapa, el alimento está podrido: "En España falta mucha información a la hora de hacer la compra: la desinformación es generalizada en cuestiones alimenticias", explica.

De acuerdo con un informe publicado por el Parlamento Europeo, 2013 será el "Año Europeo contra el Desperdicio de Alimentos". Para desechar menos comida, apunta Pérez Álvarez, es esencial conocer el producto, ya que incluso si la fecha de consumo recomendado no es próxima, la calidad puede verse alterada si el procesado, el envasado, la distribución o el almacenaje que realiza el consumidor no son adecuados. Además, es preciso mantener cierto control sobre las fechas de las etiquetas a la hora de comprar, por ejemplo, teniendo en cuenta cuándo y cómo se va a consumir el alimento, así como consultar el manual de uso que acompaña a la mayoría de productos y que puede contener especificaciones a la hora de elaborar o conservar el alimento. Aunque, según Pérez Álvarez, este control se traduciría en un ahorro considerable de dinero, ésta es una cuestión cultural y generalizada en la que juega un papel esencial la desinformación.

\section{Adiós a la dieta mediterránea}

Otro informe, publicado en 2010 por la Agencia Española de Seguridad Alimentaria y Nutrición, desvelaba también un dato llamativo: la progresiva pérdida de la dieta mediterránea, que se traduce en más carne roja, el doble de la que se recomienda, menos fruta y ver- dura, la mitad de la que se aconseja, y un consumo de pescado similar. Pérez Álvarez se lamentaba, durante la IV Semana de la Ciencia, en Torrevieja, de la progresiva limitación "del universo alimentario", fenómeno que lleva a los menores a rechazar ciertos alimentos, y a fomentar el consumo de porciones individuales y rápidas.

La psicóloga Manuela García de la Hera, profesora de Antropología de la Alimentación en la $\mathrm{UMH}$, coincide en que con la llegada de la globalización se produjo una pérdida progresiva de la dieta mediterránea, reforzada por factores como la incorporación de la mujer al mundo laboral. "Cuando una madre compra una pizza precocinada, está comprando tiempo", asegura la docente, que insiste en que las diferencias de género condicionan de forma considerable el tipo de alimentación.

Sin embargo, el $21,1 \%$ de las personas que viven en el España se encuentra bajo el umbral de la pobreza, según datos del INE (octubre de 2012). Para García de la Hera, lo primero que mueve a una persona es el instinto de supervivencia, incluso hasta el punto de consumir alimentos caducados. Según la docente, descendemos en la llamada pirámide de Maslow, por lo que la satisfacción de necesidades básicas, como la alimentación, hace que "por la salud seamos capaces incluso de vencer las barreras sociales".

+ en umhsapiens.com

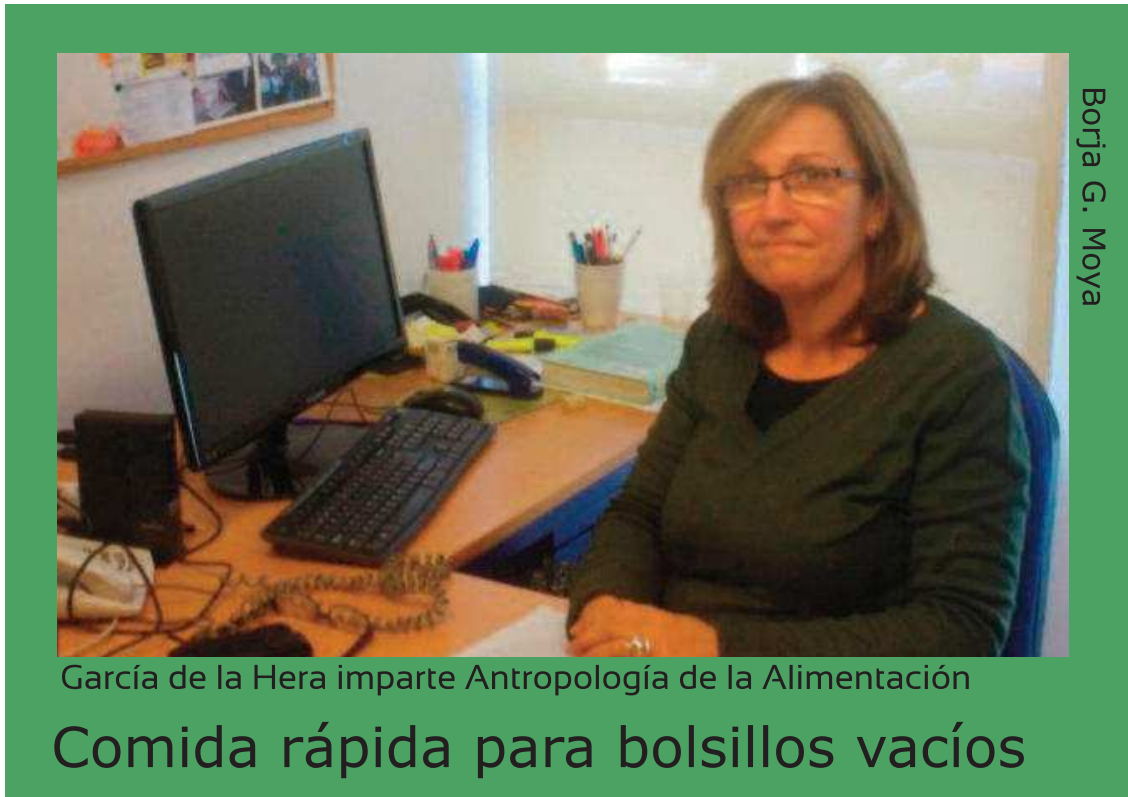

Borja G. Moya

La psicóloga García de la Hera insiste en que el principal condicionante de la alimentación de una persona es su clase social. Los tiempos de bonanza económica condujeron al consumo de marcas o a las salidas a restaurantes caros, que reforzaban el status social. En apenas cuatro años, los hábitos de consumo han cambiado y ahora se opta por llevar el tupper de casa en lugar de comer en el trabajo.
La obesidad o enfermedades cardiovasculares son características de clases más bajas, que recurren a comidas rápidas que concentran el consumo calórico diario en una sola pieza Según la docente, basta con pensar en alimentos light o ecológicos para advertir que los más sanos suelen ser más caros, algo que acaba por dirigir a personas con menor poder adquisitivo hacia un consumo poco saludable. 